\title{
Correction to: Comparison of Visual and Acoustic Emission Observations in a Four Point Bending Experiment in Barre Granite
}

\author{
Bing Qiuyi $\mathrm{Li}^{1} \cdot$ Herbert H. Einstein ${ }^{1}$
}

Published online: 31 May 2018

(c) Springer-Verlag GmbH Austria, part of Springer Nature 2018

\section{Correction to: Rock Mech Rock Eng (2017) 50:2277-2296 https://doi.org/10.1007/s00603-017-1233-z}

The authors discovered a mistake was made in the Mw calculations in this paper. To determine the spectral voltage amplitude ( $y$-axis) in the diagram in Fig. 6a we were using the periodogram function in Matlab. The mistake is that what is plotted in Fig. $6 a$ is the power i.e. the square of the spectral voltage amplitude, while the spectral voltage amplitude should be used. The updated Fig. 6a is shown below. The statements and conclusions of the research and thus of the paper are not affected but some of the numbers in the text and some of the figure need to be modified:

The changes regarding figures should be the following:

Figure 6a: change figure to:

The original article can be found online at https://doi.org/10.1007/ s00603-017-1233-z.

Bing Qiuyi Li

bingqli@mit.edu

Department of Civil and Environmental Engineering, Massachusetts Institute of Technology, Cambridge,

MA 02139, USA

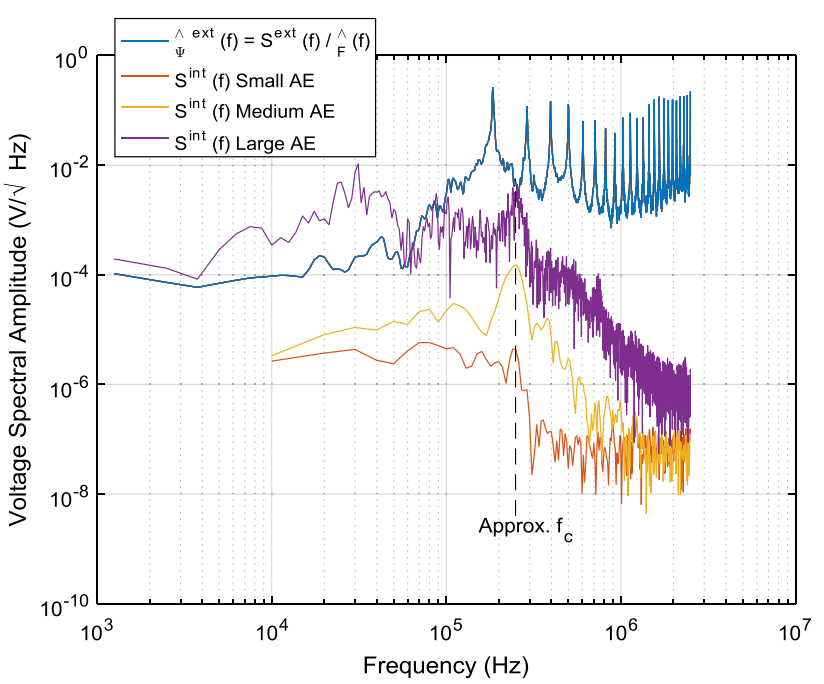

Figure 6b: change $y$-axis from " -10 to -6.5 " to " -8.2 to $-6.6 "$ ".

Figure 6: caption change from " $\mathrm{Mw}=-9.78,-8.45$ and $-6.91 "$ to "Mw $=-8.08,-7.56,-6.63 "$ "

Figure 7: $x$-axis change from " -6 to -11 " to " -6.25 to -8.75 ".

Figure 13b: the scale (right hand side) change from " -6 to -8 " to " -6.25 to -7.25 ".

Figure 15a: $x$-axis change from " -6 to -10 " to " -6.25 to -8.25 ".

Figure 15b: $x$-axis change from " -6.5 to -10 " to " -6.5 to -8.25 ".

Figure 19: Scale (right hand side) change from " -7 to -9" to " -6.75 to -7.75 ".

Figure 24: Scale (right hand side) change from " -7 to -8.5 " to " -6.75 to -7.5 ". 
The text changes should be the following:

p. 2277

Change: "Mw $=-6$ to -10 " to "Mw $=-6.25$ to -8 ".

p. 2282

Change: "Mw values were $-9.78,-8.45$ and -6.91 ," to "Mw values were $-6.63,-7.56$ and $-8.08, "$.

p. 2282

Change: "Mw $=-9.8$ to -6.25 ," to "Mw $=-8$ to -6.3 ,".

p. 2282

Change: "was calculated to be $0.74[\mathrm{Nm}=\mathrm{J}]$ " to "was calculated to be $42.83 \mathrm{Nm}$ ". p. 2285

Change: "Note that the maximum machine energy input is around $0.7 \mathrm{~J}$, which is similar to the total M0 that was calculated in the previous section." To "Note that the maximum machine energy input is around $0.7 \mathrm{~J} . "$.

p. 2294

Change: "Calibration of AE events to moment magnitudes indicate that the events vary from $\mathrm{Mw}=-6$ to -10 , with a total transformed energy of around $0.7 \mathrm{~J}$." To "Calibration of AE events to moment magnitudes indicate that the events vary from $\mathrm{Mw}=-6.25$ to $-8 .$. .

Publisher's Note Publisher's Note Springer Nature remains neutral with regard to jurisdictional claims in published maps and institutional affiliations 